\title{
LOS RETOS DE LA ECONOMÍA MEXICANA MÁS ALLÁ DE LA APERTURA COMERCIAL
}

\section{Ciro Murayama*}

\section{INTRODUCCIÓN}

La entrada en vigor del Tratado Trilateral de Libre Comercio (TLC) entre México, los Estados Unidos y Canadá, el primero de enero de 1994, significó el punto de culminación de un proceso de reforma de la economía mexicana que se inició hacia la mitad de la década de los años ochenta. Implicó, a la vez, la cristalización institucional de una integración comercial gestada a lo largo de la historia de desarrollo de la economía mexicana.

Tras la irrupción de la llamada "crisis de la deuda" en 1982, que daría lugar a lo que la CEPAL calificó para América Latina como "la década perdida", las bases y la orientación de la estrategia económica en México fueron modificadas en el afán de encontrar un nuevo modelo capaz de generar crecimiento con estabilidad, que precisó la puesta en práctica de políticas orientadas hacia la apertura externa y el acotamiento del papel estatal en la economía. El gran giro en política económica externa se registró a partir de 1985, con el ingreso de México al GATT.

Hacia el final de la década de los años ochenta, en México, tras un lustro donde lo que primó fue el ajuste económico, con medidas inscritas en lo que posteriormente se resumiría bajo la definición del "consenso de Washington", se verificó una breve etapa de crecimiento en la que fueron afinados los detalles para signar el TLC. En ese entonces, el crecimiento del producto superaba al de la población, la afluencia de capitales iba en rápido ascenso y compensando el déficit comercial, la inflación resultaba moderada y controlada, el grueso de las exportaciones se componía de productos manufacturados y no de ventas petroleras -como había ocurrido desde el inicio del proceso de industrialización en la década de los años cuarenta-, y la moneda nacional mostraba estabilidad. Se trató, de años de optimismo en los que se entendía a la economía mexicana como la representante de la nueva generación de los "milagros" protagonizados por los países emergentes en el fin de siglo; y el ingreso en esos años a la OCDE ratificaba la opinión de propios y extraños sobre la fiabilidad de las políticas adoptadas.

Sin embargo, a partir de 1994, los cambios acontecidos en el entorno económico internacional -como el alza de los tipos de interés en la economía norteamericana-, combinados, en el ámbito interno, con medidas coyunturales inadecuadas en la política económica, perfilaron un escenario que en 1995 resultaría en una nueva crisis que pondría de manifiesto problemas estructurales en la economía mexicana que un cambio de modelo no había logrado conjurar.

Así, y ya en la plena vigencia del TLC, en México se registró el peor año en el comportamiento de la economía y se alcanzaría el nivel más alto de desempleo registrado durante décadas.

Esa situación, que era de emergencia real, ha sido modificada en los años sucesivos, pero las debilidades y las asignaturas pendientes de mayor relevancia, como las que se refieren a la esfera social, están aún en vías de ser resueltas.

\section{LAS PROMESAS Y LOS RETOS DE LA APERTU- RA AL EXTERIOR}

Las coordenadas de la globalización, o si se prefiere, de la mundialización de la economía, a inicios de la actual década, parecían ser las ideales para el despegue y la consolidación del crecimiento de la economía mexicana, pues se trataba de una nación de ingreso medio, con la estructura y las cualificaciones de fuerza de trabajo correspondientes, avanzado proceso de apertura con cambios institucionales -precisamente el TLC-, situado estratégicamente en términos geográficos, etc. ${ }^{1}$. Y a pesar de que la política económica se instrumentó precisamente en la intención de aprovechar dichos elementos, la crisis de 1995 evidenció uno de los más raquíticos desempeños entre los países en desarrollo.

En los años previos, a la aplicación del libre comercio con los Estados Unidos y Canadá, los esfuerzos en cuanto a reorientación productiva habían dado como resultado un

Economista. Realiza estudios de posgrado en la Universidad Autónoma de Madrid, como becario del Consejo Nacional de Ciencia y Tecnología de México.

1. Ros, Jaime, "La crisis mexicana y la reforma de la política macroeconómica”, en Pensamiento Iberoamericano, núm. 27, CEDEAL, enero-junio de 1995. 
crecimiento sustancial del comercio exterior, de forma tal que, incluso sin TLC, podía ya hablarse de un proceso de integración económica ${ }^{2}$.

Los sectores más dinámicos se concentraban en las manufacturas para la exportación, verificándose así un cambio en los patrones de ventas al exterior, del que llegó a esperarse una reactivación del conjunto de la actividad del país si se desarrollaban las economías de escala y si ello engarzaba con la generación de empleo.

Pero en los diagnósticos, la ausencia de política industrial, o bien el hecho de que las manufacturas para la exportación ni significaban el patrón generalizado de la economía, no llevaron a una reconsideración de las líneas de actuación. La factura de tales olvidos, en 1995, la pasó la microeconomía, cuya dinámica no podía permitir, por demasiado tiempo, la adecuada marcha de la situación a nivel macro.

Cuadro 1. México: PIB por sectores \%

\begin{tabular}{|c|c|c|c|c|}
\hline Años & 1990 & 1994 & 1995 & 1996 \\
\hline TOTAL & $1000 \%$ & $100,0 \%$ & $100, \%$ & $100,0 \%$ \\
\hline IMPUESTOS A LOS PRODUCTOS NETOS DE SUBSIDIOS & $80 \%$ & $80 \%$ & $80 \%$ & $80^{\circ}$ \\
\hline VALOR AGREGADO BRUTO A PRECIOS BÁSICOS & $92,0 \%$ & $920 \%$ & $92,0 \%$ & $\overline{92,04}$ \\
\hline 1 AGROPECUARIO, SILVICULTURA Y PESCA & $6,1 \%$ & $56 \%$ & $5,8 \%$ & 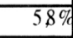 \\
\hline 2 MINERIA & $1,4 \%$ & $1,3 \%$ & $1,3 \%$ & 1,4 \\
\hline 3 INDUSTRIA MANUFACTURERA & $18,0 \%$ & $17,4 \%$ & $17,7 \%$ & $18,7 \%$ \\
\hline 4 CONSTRUCCIÓN & 420 & $46 \%$ & $3,7 \mathrm{OF}$ & $\overline{40 c}$ \\
\hline 5 ELECTRICIDAD, GAS Y AGUA & $15 \%$ & $15 \%$ & $1,6 \%$ & $16 !$ \\
\hline 6 COMERCIO, RESTAURANTES Y HOTELES & $19,7 \%$ & $20,5 \%$ & $18,7 \%$ & $18,3 \%$ \\
\hline 7 TRANSPORTE, ALMACENAJE Y COMUNICACIONES & $83 \%$ & $8,9 \%$ & $9,1 \%$ & 936 \\
\hline 8 SERVICIOS FINANCIEROS & $13,9 \%$ & $14,7 \%$ & $15,6 \%$ & $15,1 \%$ \\
\hline 9 SERVICIOS COMUNALES, SOCIALES Y PERSONALES & $21,1 \%$ & $20,4 \%$ & $21,1 \%$ & 20,4 \\
\hline CARGO POR SERVICIOS BANCARIOS IMPUTADOS & $-2,30$ & $-2,9$ व & $-2,8 \%$ & $-2,5$ \\
\hline
\end{tabular}

Un acercamiento al perfil general de la economía mexicana evidencia una composición del producto con características de una economía moderna, que ha superado las etapas de amplia dependencia de la actividad primaria y que, por el contrario, cuenta con un peso importante de las actividades industriales y una aportación más significativa del sector servicios.

Cuadro 2. Crecimiento anual del PIB por sectores

\begin{tabular}{|l|r|r|r|r|}
\hline & 1990 & 1994 & 1995 & 1996 \\
\hline TOTAL & $5,1 \%$ & $4,5 \%$ & $-6,2 \%$ & $5,1 \%$ \\
\hline IMPUESTOS A LOS PRODUCTOS NETOS DE SUBSIDIOS & $5,1 \%$ & $4,4 \%$ & $-6,2 \%$ & $5,2 \%$ \\
\hline VALOR AGREGADO BRUTO A PRECIOS BASICOS & $5,1 \%$ & $4,5 \%$ & $-6,2 \%$ & $5,1 \%$ \\
\hline I AGROPECUARIO, SILVICULTURA Y PESCA & $5,6 \%$ & $0,9 \%$ & $-2,5 \%$ & $4,8 \%$ \\
\hline 2 MINERIA & $3,4 \%$ & $2,5 \%$ & $-3,4 \%$ & $9,2 \%$ \\
\hline 3 INDUSTRIA MANUFACTURERA & $6,8 \%$ & $4,1 \%$ & $-4,6 \%$ & $10,6 \%$ \\
\hline 4 CONSTRUCCION & $9,2 \%$ & $8,4 \%$ & $-23,3 \%$ & $11,2 \%$ \\
\hline 5 ELECTRICIDAD, GAS Y AGUA & $2,6 \%$ & $4,8 \%$ & $2,1 \%$ & $4,5 \%$ \\
\hline 6 COMERCIO, RESTAURANTES Y HOTELES & $6,2 \%$ & $6,8 \%$ & $-14,1 \%$ & $2,4 \%$ \\
\hline 7 TRANSPORTE, ALMACENAJE Y COMUNICACIONES & $3,6 \%$ & $8,7 \%$ & $-4,5 \%$ & $8,3 \%$ \\
\hline 8 SERVICIOS FINANCIEROS & $4,4 \%$ & $5,4 \%$ & $-0,4 \%$ & $1,5 \%$ \\
\hline 9 SERVICIOS COMUNALES, SOCIALES Y PERSONALES & $3,1 \%$ & $1,3 \%$ & $-2,9 \%$ & $1,6 \%$ \\
\hline CARGO POR SERVICIOS BANCARIOS IMPUTADOS & $6,7 \%$ & $11,1 \%$ & $-9,0 \%$ & $-5,8 \%$ \\
\hline Fuente: INEGI & & & \\
\hline
\end{tabular}

Ahora bien, los efectos de la crisis sobre la actividad por sectores en 1995, que muestra el cuadro 2, dan cuenta de la magnitud de la caída. El repunte de 1996 no logra compensar la situación prevaleciente en 1994 e, incluso, si se atienden a series estadísticas más amplias, a los que se llegó al comienzo de la década de los ochenta.
Siguiendo las consecuencias de la crisis, se observa que la restricción crediticia y el elevado endeudamiento de las empresas, conjugados con la caída de la demanda, dieron lugar a una caída del producto del 6,19\% y una tasa de paro del $7,6 \%$ en agosto de 1995 , la más alta registrada en la historia moderna del país.

Asimismo, la drástica disminución de la oferta no implicó un cambio notable en su estructura. Y la demanda, por su parte, resultó favorecida en las exportaciones gracias a la devaluación ocurrida hacia el fin de 1994 y exacerbada en los primeros meses de 1995. Pero ese aumento, no consiguió revertir en el agregado la mala situación producida por la caída ocurrida en el mercado interno. (Cuadros 3 y 4 ).

Cuadro 3. El comportamiento de la oferta y demanda

\begin{tabular}{|l|r|r|r|}
\hline \multicolumn{4}{|c|}{ México: Oferta y Demanda Agregadas } \\
\hline \multicolumn{3}{|c|}{ Estructura porcentual } \\
\hline & \multicolumn{1}{|c|}{1994} & \multicolumn{1}{|c|}{1995} & \multicolumn{1}{|c|}{1996} \\
\hline Oferta total & 100.0 & 100.0 & 100.0 \\
\hline PIB & 81.9 & 82.8 & 82.8 \\
\hline Importación de bienes y servicios & 18.1 & 17.2 & 17.2 \\
\hline Demanda Total & 100.0 & 100.0 & 100.0 \\
\hline Consumo privado & 59.0 & 59.2 & 59.2 \\
\hline Consumo de Gobierno & 8.9 & 9.0 & 9.0 \\
\hline Formación bruta de capital fijo & 15.8 & 12.1 & 12.1 \\
\hline Variación de existencias & 2.3 & -0.9 & -0.9 \\
\hline Exportación de bienes y servicios & 14.0 & 20.7 & 20.7 \\
\hline Fuente: INEGI & \multicolumn{3}{|}{} \\
\hline
\end{tabular}

Cuadro t. Evolución de la demanda y oferta

\begin{tabular}{|c|c|c|c|}
\hline \multicolumn{4}{|l|}{ Variación porcentual anual } \\
\hline & 1994 & 1995 & 1996 \\
\hline Oferta total & 7 & -7.4 & 9 \\
\hline$\overline{P I B}$ & 4.5 & -6.1 & 5.1 \\
\hline Importación de bienes y servicios & 20.5 & -12.8 & 27.8 \\
\hline \begin{tabular}{|l|} 
Demanda Total \\
\end{tabular} & 7 & -7.4 & 9 \\
\hline Consumo privado & 4.6 & -9.5 & 2.3 \\
\hline Consumo de Gobiemo & 2.9 & -1.3 & 3.7 \\
\hline Formación bruta de capital fijo & 8.4 & -29 & 17.7 \\
\hline Exportación de bienes y servicios & 17.4 & 33 & 18.7 \\
\hline
\end{tabular}

De ahí que la devaluación fuera neutralizada por el aumento del índice de precios y del valor del dinero, disparados en la intención de contener y retornar divisas al mercado financiero de forma tal que hubiese reservas para hacer frente a las obligaciones hechas en moneda estadounidense.

La crisis de mediados de los noventa, inicialmente calificada como financiera ${ }^{3}$, vino a demostrar al menos tres tipos de problemas: de liquidez, de confianza y estructurales. Los dos primeros, sobre todo, habrían de ser enfrentados en plena emergencia desde los primeros meses de 1995

2. Yendo más atrás en las series, se constata que, por ejemplo, desde 1980 el $65 \%$ de las exportaciones mexicanas tuvieron como destino los Estados Unidos y el $62 \%$ de las importaciones las obtenía México de ese país. En 1995 las cifras son $83 \%$ y 74\% respectivamente. Véase Nacional Financiera, La economía mexicana en cifras 1996, México, 1997.

3. Sobre los diversos diagnósticos y lecturas de la crisis en el año 1995, véase Cordera Campos, Rolando, 1995: la economia mexicana en peligro, México, Cal y Arena, 1997. 
Desde una perspectiva más amplia, los desequilibrios estructurales se constatan en un proceso inacabado de modernización institucional y del aparato productivo interno para insertarse exitosamente en la economía internacional, con capacidad de absorber por entero los acomodos asociados al cambio de modelo de desarrollo. Asimismo, los problemas financieros por los costes presentes impiden satisfacer, con recursos propios, la inversión, el servicio de la deuda externa y la reestructuración de la banca. En el orden social, hay una intensificación de la injusticia distributiva. Aunado a lo anterior, existe un desequilibrio en las estrategias públicas, ya que en ellas predominan enfoques segmentados o secuenciales inscritos en el puro horizonte de la estabilización macroeconómica, que ha desplazado la preocupación por la reconstrucción de las estructuras e instituciones que harían viable el desarrollo ${ }^{4}$.

Ahora bien, cabe mencionar que en el patrón seguido en tiempos recientes por la economía mexicana, el crecimiento de las exportaciones va acompañado también por un efecto adverso al presentarse un desplazamiento de la producción local por importaciones, que ha dado lugar ya a estimaciones sobre capacidad industrial instalada ociosa del $27 \%{ }^{5}$.

De particular interés resulta el comportamiento del sector manufacturero (Cuadro 5) en virtud de que es el generador de bienes transables, que también registró un declive generalizado en 1995, por lo cual el "boom" exportador de ese mismo año tampoco dio el tirón suficiente para siquiera sacar a flote este renglón de actividad que es el de mayor productividad en el trabajo.

Cuadro 5. México: PIB de la Industria Manufacturera por división de actividad económica

\begin{tabular}{|c|c|c|c|c|c|c|c|c|c|c|}
\hline \multicolumn{11}{|c|}{ Distribución por sectores } \\
\hline Año & Total & $\mathrm{I}$ & II & III & IV & $\mathrm{V}$ & $\mathrm{VI}$ & VII & VIII & $\mathrm{IX}$ \\
\hline 1990 & $100,0 \%$ & $26,0 \%$ & $9,4^{\circ} \circ$ & $3.4^{\circ} \mathrm{O}$ & $5,2 \%$ & $16,9 \%$ & $7,6 \%$ & $4,7 \%$ & $23,9 \%$ & $2,8^{\circ} \circ$ \\
\hline 1994 & $100,0 \%$ & $26,8 \%$ & $8.5 \%$ & $3.2 \%$ & $5,1 \%$ & $15,8 \%$ & $8,0 \% 7$ & $4,5 \%$ & 25,2 积 & $2,9 \%$ \\
\hline 1995 & $100,0 \%$ & $28,10 \%$ & 8,4 年 & $3,1 \%$ & $4.9 \%$ & $16,5 \%$ & $7,4 \%$ & $4,9 \%$ & $23,89$. & $2,8 \%$ \\
\hline 1996 & $100,0 \%$ & $26,2 \%$ & $8,9 \%$ & $2,9 \%$ & $4,5 \%$ & 15,7\% & $7,5 \%$ & 5,39 & 26,109 & $2,8 \%$ \\
\hline \multicolumn{11}{|c|}{ Crecimiento anual } \\
\hline 1990 & $6,8^{\circ} \circ$ & $4,5^{\circ} \cdot$ & $5,8^{\circ} \cdot$ & $-0,4^{\circ} \%$ & $8,0^{\circ} \%$ & $4,3 \%$ & $6,5 \%$ & $7,2 \%$ & $11,2^{\circ} \circ$ & $18,1^{\circ} \%$ \\
\hline 1994 & 4,100 & 3,39 & $1,1 \mathrm{~m}$ & 1.99 & 2,9 牙 & $3,4 \%$ & 4,69 和 & $6,2 \%$ & 6,79 & $2,2 \%$ \\
\hline 1995 & $-4.8 \%$ & $0.0 \%$ & $-63 \%$ & $-7.7 \%$ & $-7,600$ & $-0.9 \%$ & $-11.6 \%$ & $3,8 \%$ & $-9,8 \%$ & $-10.1 \%$ \\
\hline 1996 & $10,9 \%$ & 3.29 & $18.5 \%$ & $5,00 \%$ & 0,0 乘 & $5.8 \%$ & 11.49 & $19,9 \%$ & 21,40 & $13.1 \%$ \\
\hline \multicolumn{11}{|c|}{ I Productos alimenticios, bebidas y tabaco. } \\
\hline \multicolumn{11}{|c|}{ II Textiles, prendas de vestir e industria del cuero. } \\
\hline \multicolumn{11}{|c|}{ III Industria de la madera y productos de madera } \\
\hline \multicolumn{11}{|c|}{ IV Papel, productos de papel, imprenta y editoriales } \\
\hline \multicolumn{11}{|c|}{ V Sustancias quimicas, derivados del petróleo, productos de caucho y plástico } \\
\hline \multicolumn{11}{|c|}{\begin{tabular}{|ll} 
Vl Productos de minerales no metálicos, excepto derivados del petróleo y carbón \\
\end{tabular}} \\
\hline \multicolumn{11}{|c|}{ VII Industrias metálicas básicas } \\
\hline \multicolumn{11}{|c|}{ VIII Productos metálicos, maquinaria y equipo } \\
\hline \multicolumn{11}{|c|}{\begin{tabular}{|l|l|} 
IX & Otras industrias manufactureras \\
\end{tabular}} \\
\hline \multicolumn{11}{|c|}{ Fuente: INEGI. } \\
\hline
\end{tabular}

De manera específica, las exportaciones manufactureras (Cuadro 6) se vieron favorecidas por la puesta en práctica del TLC (más del 30\% de incremento en el primer año), lo cual, en combinación con la ganancia en competitividad que dio la subvaluación del peso, constituye la aportación central, más significativa, del Tratado en el conjunto de la economía mexicana.

En lo que hace a las importaciones manufactureras (Cuadro 7), si bien decrecieron por las causas ya señaladas de contracción de la demanda en el segundo año de vigencia
Cuadro 6. Exportaciones mamufactureras

\begin{tabular}{|c|c|c|c|c|c|c|c|c|}
\hline \multicolumn{9}{|c|}{ Exportaciones manufactureras (Millones de Dólares) } \\
\hline & 1994 & $\%$ & 1995 & $\%$ & $\begin{array}{c}\text { crec. } \\
\%\end{array}$ & $1996^{*}$ & $\%$ & crec. $\%$ \\
\hline Total de las industrias manufactureras & $51,075.2$ & 100 & 67382.9 & 100 & 31,9 & 73880.2 & 100 & 9,6 \\
\hline Alimentos, bebidas y tabaco & $1,895.6$ & 3.7 & 2528.5 & 3.8 & 33,4 & 2699.2 & 3.7 & 6,8 \\
\hline $\begin{array}{l}\text { Textiles, prendas de vestir, e industria } \\
\text { del cuero }\end{array}$ & $3,255.8$ & 6.4 & 4899 & 7.3 & 50,5 & 5817 & 7.9 & 18,7 \\
\hline Industria y productos de la madera & 586.1 & 1.1 & 619.5 & 0.9 & 5.7 & 793.3 & 1.1 & 28,1 \\
\hline $\begin{array}{l}\text { Papel, productos del papel, imprentay } \\
\text { editoriales }\end{array}$ & 561.6 & 1.1 & 871.8 & 1.3 & 55,2 & 797.1 & 1.1 & $-8,6$ \\
\hline Productos petroleros & 544.5 & 1.1 & 652.9 & 1.0 & 19,9 & 569.9 & 0.8 & $-12,7$ \\
\hline Petroquimicos & 263.0 & 0.5 & 339.9 & 0.5 & 29,3 & 230.3 & 0.3 & -32.2 \\
\hline Quimicos & 2.756 .4 & 5.4 & 3971.8 & 5.9 & 44,1 & 3695.8 & 5.0 & $-6,9$ \\
\hline y caucho & $1,064.4$ & 2.1 & 1217.6 & 1.8 & 14,4 & 1308.2 & 1.8 & 7.4 \\
\hline Minerales no metálicos & $1,214.8$ & 2.4 & 1404.5 & 2.1 & 15,6 & 1572.1 & 2.1 & 11,9 \\
\hline Carbón y acero & 1.534 .7 & 3.0 & 3087.6 & 4.6 & 101.2 & 2808 & 3.8 & -9.1 \\
\hline Industrias metál & $1,085.1$ & 2.1 & 1800.9 & 2.7 & 66,0 & 1570.8 & 2.1 & .12 .8 \\
\hline $\begin{array}{l}\text { Productos metálicos, mquinaria y } \\
\text { equipo }\end{array}$ & $35,327.4$ & 69.2 & 44680.6 & 66.3 & 26,5 & 50722.3 & 68.7 & 13,5 \\
\hline Otras industrias & 989.0 & 1.9 & 1308.3 & 1.9 & 32,3 & 1296.4 & 1.8 & $-0,9$ \\
\hline
\end{tabular}

Cuadro 7. Importaciones manufactureras (Millones de Dólares)

\begin{tabular}{|c|c|c|c|c|c|c|c|c|c|}
\hline & 1994 & $\%$ & $\begin{array}{l}\text { cre } \\
\text { c. } \%\end{array}$ & 1995 & $\%$ & \begin{tabular}{|l|}
$\mathrm{cre}$ \\
$\mathrm{c} . \%$ \\
\end{tabular} & $1996^{\circ}$ & $\%$ & $\begin{array}{c}\text { crec. } \\
\%\end{array}$ \\
\hline Total de las industrias manufactureras & $74,424.7$ & 100 & 21 & 67500 & 100 & -9 & 73880.2 & 100 & \\
\hline Alimentos, bebidas y tabaco & $3,988.9$ & 5.4 & 19 & $2,616.4$ & 3.9 & .34 & 2699.2 & 3.7 & \\
\hline $\begin{array}{l}\text { Textiles, prendas de vestir, e industria } \\
\text { del cuero }\end{array}$ & $4,167.4$ & 5.6 & 18 & $3,617.6$ & 5.4 & .13 & 5817 & 7.9 & \\
\hline Industria y productos de la madera & 695.1 & 0.9 & 22 & 350.1 & 0.5 & .50 & 793.3 & 1.1 & \\
\hline $\begin{array}{l}\text { Papel, productos del papel, imprenta y } \\
\text { editoriales }\end{array}$ & $3,039.2$ & 4.1 & 28 & $2,898.7$ & 4.3 & -5 & 797.1 & 1.1 & \\
\hline Productos petroleros & $1,275.4$ & 1.7 & .7 & 1.242 .6 & 1.8 & -3 & 569.9 & 0.8 & \\
\hline Petroquimicos & 758.0 & 1.0 & 26 & 920.1 & 1.4 & 21 & 230.3 & 0.3 & \\
\hline Químicos & 5.817 .7 & 7.8 & 20 & $5,520.4$ & 8.2 & -5 & 3695.8 & 5.0 & \\
\hline Productos de plástico y caucho & $3,972.4$ & 5.3 & 17 & 4.157 .0 & 6.2 & 5 & 1308.2 & 1.8 & \\
\hline Minerales no metálicos & $1,010.1$ & 1.4 & 23 & 910.0 & 1.3 & -10 & 1572.1 & 2.1 & \\
\hline Carbón y acero & $3,930.9$ & 5.3 & 19 & $3,693.0$ & 5.5 & -6 & 2808 & 3.8 & \\
\hline Industrias metálicas básicas & $1,194.0$ & 1.6 & 23 & $1,203.5$ & 1.8 & -1 & 1570.8 & 2.1 & \\
\hline $\begin{array}{l}\text { Productos metálicos, maquinaria y } \\
\text { equipo }\end{array}$ & 43,490 & 58.4 & 22 & 39,709 & 58.8 & -9 & 50722.3 & 68.7 & \\
\hline Otras industrias & $1,086.0$ & 1.5 & 45 & 661.7 & 1.0 & .39 & 1296.4 & 1.8 & \\
\hline
\end{tabular}

del TLC, muestran una recuperación para 1996, y ya en 1997 se registró un ligero déficit comercial, puesto que las exportaciones desaceleraron su crecimiento respecto al ejercicio anterior. La rápida expansión de las importaciones apenas se inicia el crecimiento, puede ser explicado por la destrucción de buena parte de la red de nexos interindustriales producto de la drástica apertura al exterior que se concretó en menos de una década, pues entre 1987 y 1996 la ponderación del comercio exterior en el producto pasó del 30\% al 55\% y las importaciones duplicaron su participación en la oferta global ${ }^{6}$.

Sin embargo, la diversificación de las ventas al exterior, respecto, por ejemplo, a los años en que se inició la crisis previa, la de la deuda, permite afirmar que la economía mexicana efectivamente está en mejores condiciones, sin dejar de reconocer los lastres existentes, de insertarse en los mercados internacionales. En la actualidad, lo que hace tan sólo tres lustros representaba el $80 \%$ de las ventas al exterior, significa exclusivamente un $10-11 \%$ (Cuadros 8 y 9). Sin embargo, a medio y largo plazo se detecta un creciente problema de pérdida de eficiencia de las exportaciones manufactureras ${ }^{7}$

4. Ibarra, David, "La economía mexicana: ¿en dónde estamos?", en Nexos, núm. 235, julio de 1997

5. López, Julio, "La industria mexicana ante la crisis" UACPyP UNAM, México, (mimeo) 1996.

6. Ibarra, David, op. cit.

7. Loria, Eduardo, "Los efectos de la apertura comercial sobre el empleo y la balanza comercial del sector manufacturero mexicano, 1986 1996” en Ruesga, Santos (comp.), Integración Económica Regional (en prensa) Madrid, 1998. 
Cuadro 8. Balanza comercial (millones de dólares)

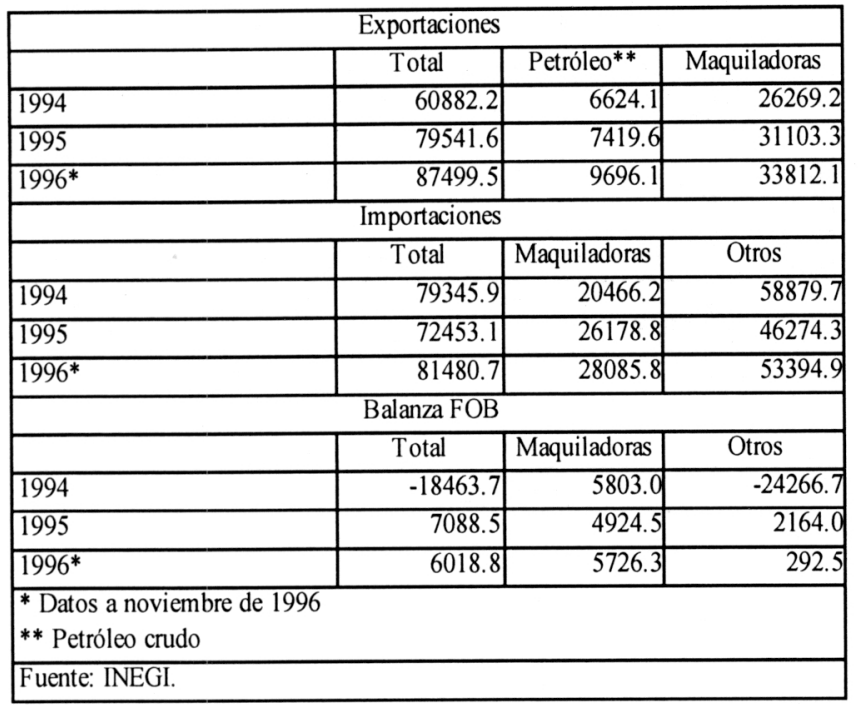

Cuadro 9. Estructura porcentual

\begin{tabular}{|l|r|r|r|r|r|r|r|}
\hline & \multicolumn{9}{|c|}{ Exportaciones } & \multicolumn{3}{c|}{ Importaciones } \\
\hline & Total & Petroleras** & Maquiladoras & Otros & Total & Maquiladoras & Otros \\
\hline 1994 & 100.0 & 10.9 & 43.1 & 56.9 & 100.0 & 25.8 & 74.2 \\
\hline 1995 & 100.0 & 9.3 & 39.1 & 60.9 & 100.0 & 36.1 & 63.9 \\
\hline $1996^{*}$ & 100.0 & 11.1 & 38.6 & 61.4 & 100.0 & 34.5 & 65.5 \\
\hline $\begin{array}{l}\text { * Datos a noviembre de } 1996 \\
\text { ** Petróleo crudo }\end{array}$ \\
Fuente: INEGI. \\
\hline
\end{tabular}

En la antesala de la última crisis, se tuvo un modelo donde se combinaban liberalización del comercio exterior con apreciación cambiaria en términos reales, plena liberalización financiera externa, bajas tasas de ahorro e inversión, y pocos esfuerzos específicos de promoción de exportaciones y políticas sectoriales de apoyo ${ }^{8}$. De mantenerse dicho esquema, y sólo introduciendo un cambio en la política cambiaria como de hecho ya ha ocurrido, las posibilidades de articular la economía y reanimar el mercado interno en la senda de un crecimiento durable y generador de empleo no parecen ser amplias.

Aunado a lo anterior, es de resaltar la incapacidad de la economía mexicana para generar ahorro, así como el alto nivel de dependencia de los flujos de capitales del exterior, que en 1994-95 la colocaron en una situación extrema de vulnerabilidad ante las oscilaciones de los mercados internacionales.

Por otra parte, la apreciación de la moneda hasta el fin de 1994, que fue en realidad una sobrevaluación del peso, al modificar de manera creciente los precios relativos en contra del sector productor de bienes comerciables a nivel internacional, acarrea una reducción de los niveles de rentabilidad que acaba afectando los de por sí bajos niveles de ahorro empresarial. De ahí que se exacerbe la dependencia de las entradas de capital de cartera (Cuadros 12 a 14). El haber incurrido en un déficit por cuenta corriente del $8 \%$ del producto en el primer año del TLC es muestra significativa del nivel de dependencia.

Por lo hasta ahora dicho, la economía mexicana está cada vez más inserta a los flujos financieros y comerciales del mundo, en particular de los Estados Unidos, con los riesgos y la mayor vulnerabilidad ante las oscilaciones en
Cuadro 10. Tasa de crecimiento media amual por tipo de bien

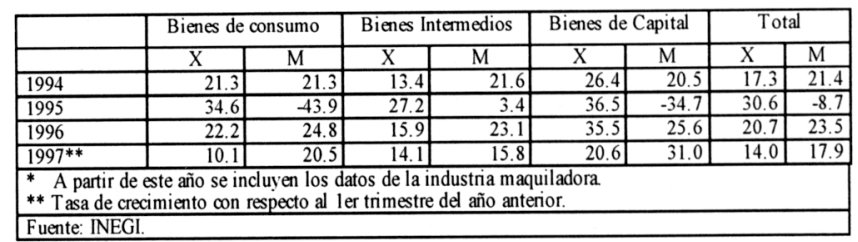

Cuadro 11. México: Cuentas Externas 1994-1996

\begin{tabular}{|l|c|c|c|c|c|c|}
\hline \multicolumn{7}{|c|}{ (millones de dólares) } \\
\hline & $\begin{array}{c}\text { Cuenta } \\
\text { corriente }\end{array}$ & $\begin{array}{c}\text { Balanza } \\
\text { comercial }\end{array}$ & $\begin{array}{c}\text { Balanza en } \\
\text { cuenta de } \\
\text { capital }\end{array}$ & Reservas & $\begin{array}{c}\text { PIB* } \\
\text { (millones de } \\
\text { pesos en 1993) }\end{array}$ & $\begin{array}{c}\text { Tasa de } \\
\text { crec. del } \\
\text { PIB }\end{array}$ \\
\hline 1994 & $-29,662.0$ & $-18,463.7$ & $14,584.2$ & -18389.3 & 1312200.4 & 4.46 \\
\hline 1995 & $-1,578.0$ & $7,088.5$ & $15,652.0$ & 9592.8 & 1230925.0 & -6.19 \\
\hline 1996 & -1762.0 & 6531.0 & 3604.0 & 1768.0 & 1293617.5 & 5.1 \\
\hline
\end{tabular}

Cuadro 12. Cuenta de capital

\begin{tabular}{|c|c|c|c|c|c|c|c|}
\hline \multirow[b]{3}{*}{ Año } & \multirow{3}{*}{ Saldo } & \multicolumn{5}{|c|}{ Pasivos } & \multirow[t]{3}{*}{ Activos } \\
\hline & & \multirow[t]{2}{*}{ Total } & \multirow{2}{*}{$\begin{array}{l}\text { Préstamos y } \\
\text { depósitos }\end{array}$} & \multicolumn{3}{|c|}{ Inversión Extranjera } & \\
\hline & & & & \begin{tabular}{|l|l|} 
Total \\
\end{tabular} & \begin{tabular}{|l|} 
Directa \\
\end{tabular} & De cartera & \\
\hline 1994 & $\overline{14584.3}$ & $\overline{20254.2}$ & 1099.5 & 19154.7 & 10972.5 & 8182.2 & -5670.0 \\
\hline 1995 & 14331.0 & 22500.3 & 23288.9 & -788.6 & 9226.1 & -10014.7 & -8369.0 \\
\hline 1996 & 3603.5 & 10059.8 & -11628.6 & 21688.4 & 7534.6 & 14153.8 & -6456.3 \\
\hline
\end{tabular}

Cuadro 13. Inversión extranjera \%

\begin{tabular}{|c|c|c|c|}
\hline & Total & Directa & De Cartera \\
\hline 1994 & 100.0 & 57.3 & 42.7 \\
\hline 1995 & 100.0 & -1169.9 & 1269.9 \\
\hline 1996 & 100.0 & 34.7 & 65.3 \\
\hline
\end{tabular}

Cuadro 14. México: Servicio de la deuda pública externa

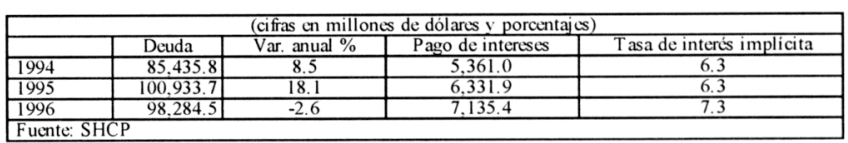

otras economías que ello lleva consigo, pero a la vez no se ha sido capaz de articular adecuadamente el mercado interno.

Las limitaciones, en lo que hace a la consolidación de una estructura productiva dinámica y con condiciones de competir y, sobre todo, de generar bienestar, pueden ser enfocadas desde el mirador del mercado de trabajo mexicano, que es lo que nos proponemos a continuación.

\section{EL EMPLEO EN LOS AÑOS DE APERTURA COMERCIAL}

México presenta una dinámica alta en el crecimiento de su población económicamente activa por dos razones fundamentales: tasas de natalidad elevadas, sobre todo en los años setenta, y la mayor participación de las mujeres?. Así, la población que ofrece trabajo y demanda bienestar ya nació. Es de resaltar el hecho de que, por vez primera desde los albores del actual siglo, hay ya una generación

8. Ros, Jaime, "La enfermedad mexicana", en Nexos, núm. 235 , México, julio de 1997.

9. Rendón, T. y Salas, C. "La evolución del empleo en México: 1895-1980"; Estudios Demográficos y Urbanos, Vol II, núm. 2, El Colegio de México, 1987. 
completa de mexicanos que ha vivido, siempre, con la crisis económica como telón de fondo, o nubarrón, a sus quehaceres y aspiraciones. Por lo anterior, en México, sea cual fuese la estrategia para alcanzar el crecimiento, tiene que ser una que incorpore en sus metas la creación de empleo. Tan es así que, si tan sólo se persigue no empeorar los desequilibrios existentes entre oferta y demanda en el mercado de trabajo, el crecimiento general de la economía habría de resultar mayor, para los próximos años, al registrado en los últimos tres lustros. Es decir, se necesitaría crecer a una tasa mínima de 5,19\% hasta el año 2002. Esa sería, como argumenta Rolando Cordera, el "mínimo técnico" para hacer posible enfrentar los objetivos de equidad que se plantean desde y para la sociedad mexicana.

Mientras que la población económicamente activa, entre 1980 y 1996, creció a una tasa media anual del 3,6\%, es decir en un $77 \%$, el empleo en las manufacturas, que sería el segmento modernizado de la economía de mercado, declinó su participación en la población activa en un $50 \%$, siendo la reducción de un $18 \%$ en términos absolutos. La OIT calcula que el $60 \%$ de los empleos se ubica en el sector informal de la economía -si se consideran trabajadores independientes, servicio doméstico y pequeñas empresas ${ }^{10}$.

En el mismo sentido, es de mencionar que la tendencia declinante de la capacidad del sector productor de bienes comerciables para crear puestos de trabajo es continua desde antes que la estrategia de crecimiento fuera modificada en los ochenta. Las conductas presentadas por el mercado de trabajo consisten en una caída del trabajo asalariado y en una expansión de los empleos por cuenta propia. Es decir, que la economía mexicana se enfrenta a un problema cada vez más grave de disminución en la calidad del empleo ${ }^{11}$, mismo que habría de ser enfrentado con medidas que trasciendan las puras intenciones de integración y apertura externa que, por sí mismas, no son capaces de revertir la desfavorable dinámica del empleo.

Además, en la medida que hay algo de crecimiento, se trata de uno impulsado por el sector de bienes no comerciables que absorbe la fuerte expansión de la fuerza de trabajo, con mala remuneración y niveles bajos de productividad ${ }^{12}$. La caída del valor agregado por trabajador entre 1989 y 1996 está entre el 6\% y el 8\%, porque la ocupación se concentró en empleos informales o de baja productividad comparativa. Además, ante el cambio de entorno existente, las grandes empresas, en general, han reconvertido sus producciones, elevando sus coeficientes de capitalización y racionalizando plantillas de personal; en lo que se refiere a los fabricantes pequeños y medianos, cuya producción se orienta al mercado interno, han concentrado sus esfuerzos de ajuste en reducir ocupación y salarios reales ${ }^{13}$.

Asimismo, cabe señalar que los crecientes niveles de déficit comercial que viene acusando la economía mexicana, tienen alta correlación con la disminuida capacidad del sector manufacturero de crear nuevos puestos de trabajo ${ }^{14}$.

Por otra parte, la inversión extranjera directa, que se esperaba iba a potenciar la generación de empleo, se ha dirigido en su gran mayoría a la compra de empresas ya existentes, más que a la creación de nuevos establecimientos productivos, como ha sucedido con el grueso de las economía latinoamericanas.

En este contexto, es de esperar que abunden las estrategias de sobrevivencia, es decir, que se extienda el autoempleo en pequeñas unidades de servicios, en particular del comercio al por menor. Esta actividad, descontando sólo a las agropecuarias que desde hace décadas no absorben fuerza de trabajo, involucraba por sí misma al contingente más amplio de la población ocupada en 1995 (Cuadro 15).

\section{Gráfico 1}

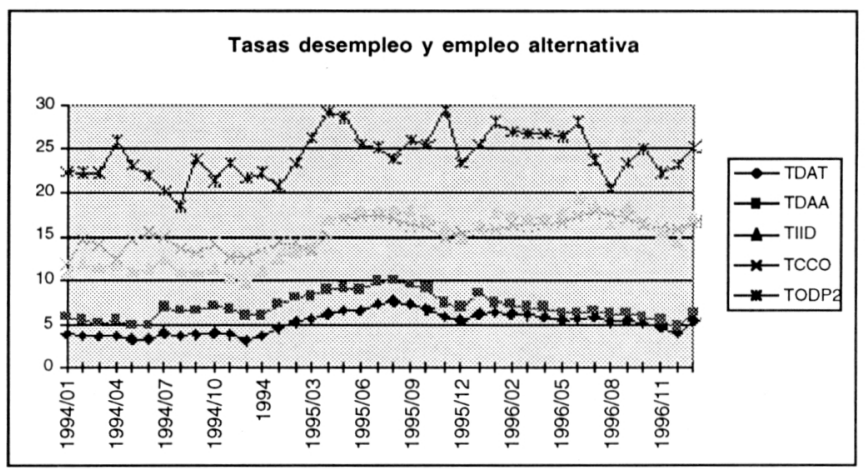

Fuente: INEGI.

TDAT: Tasa de desempleo abierto tradicional: Son las personas de 12 años y más que en la semana de referencia:

- No trabajaron

- Se encontraban disponibles para realizar una actividad económica

- Buscaron empleo en los 2 meses previos, sin encontrarlo.

TDAA: Tasa de desempleo abierto alternativa: Considera no sólo a los desocupados abiertos, sino a la parte de la población económicamente inactiva que suspendió la búsqueda de empleo pero que está en condiciones de trabajar.

TOPD2: Tasa de ocupación y desocupación 2: Es el porcentaje que representan los desocupados y los ocupados que laboran menos de 35 horas a la semana por razones de mercado, respecto de la PEA.

TIID: Tasa de ingresos inferiores al mínimo y desocupación: Considera a los desocupados y a los ocupados que reciben ingresos inferiores al salario mínimo.

TCCO: Tasa de condiciones críticas de ocupación: Es la proporción de los ocupados que trabajan menos de 35 horas a la semana, más de 35 horas con ingresos inferiores al salario mínimo, o más de 48 horas ganando menos de 2 salarios mínimos.

Las distintas tasas de desempleo (Gráfico 1) registradas a lo largo de los tres primeros años de vigencia del TLC muestran que la incapacidad para generar puestos de trabajo con remuneraciones adecuadas sigue siendo, junto con el problema de concentración del ingreso, la mayor asignatura pendiente de la economía mexicana para arrojar resultados mínimamente satisfactorios en la esfera social.

10. Ibarra, David, op. cit.

11. Rendón, Teresa y Salas, Carlos, "El impacto probable del TLC sobre el empleo no agrícola en México", en Martín, Pablo y Salas, Carlos (comps.), Cuestiones de integración y desarrollo, UNAM-UAM, Madrid, 1996.

12. Ros, Jaime, op. cit.

13. Ibarra, David, $o p$. cit

14. Loria, op. cit. 
La catástrofe en las remuneraciones al trabajo no hizo sino incrementarse con la crisis de 1995, como era obvio, y para un año después puede apreciarse el margen de pobreza que padece incluso la población empleada (Gráfico 2). Pero esta tendencia viene desde la crisis de 1982, pues desde entonces la participación de los asalariados en el ingreso nacional ha caído en doce puntos y el salario mínimo, ha perdido cerca del $70 \%$ de su poder adquisitivo ${ }^{15}$.

Cuadro 2

\section{Salarios mensuales como proporción del salario mínimo, 1996}

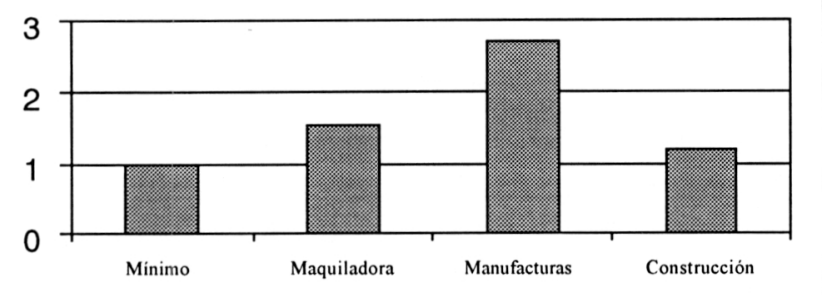

Mientras tanto, las percepciones en el sector manufacturero (Gráfico 3), incapaz de generar empleo en abundancia, siguen cayendo, lo que viene a constatar una situación donde la brecha entre salarios y productividad se amplía y en la cual los círculos virtuosos simplemente no se reflejan en ningún indicador. Las diferencias en productividad entre México y sus principales socios comerciales, que exacerban la disparidad en la remuneración, evidencian que el país latinoamericano sigue siendo por definición un exportador de mano de obra barata ${ }^{16}$.

Gráfico 3

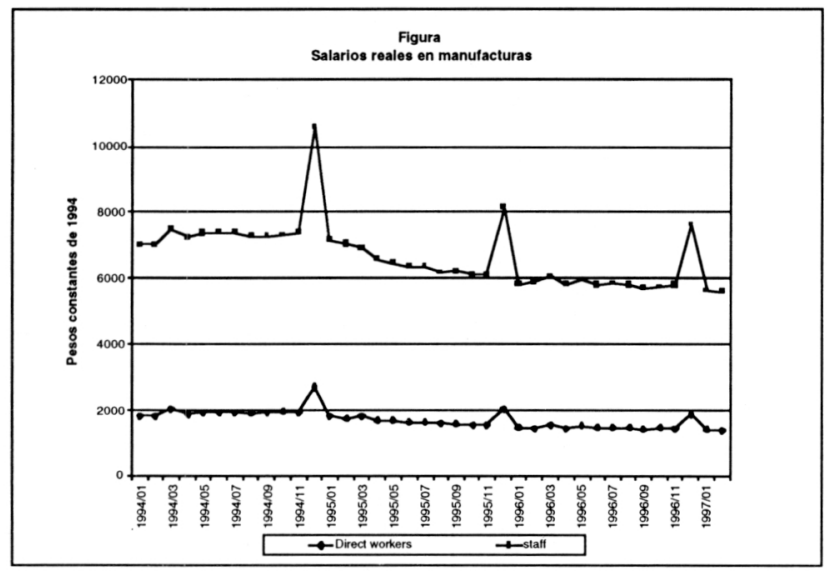

Asimismo, puede constatarse que, en los últimos años, ha crecido en promedio, respecto a la situación de arranque de la década, la franja de la población con remuneraciones por debajo del salario mínimo (Gráfico 4). Y, como demuestran múltiples estudios, ese ingreso es de un monto pecuniario inferior al que se precisa para cubrir una canasta de necesidades básicas.

La magnitud de la deuda social, incluso para quienes tienen un empleo, es evidente. De forma general, si en 1985 el Banco Mundial comparaba el ajuste mexicano de entonces, en términos de exportaciones, reducción del PIB y consumo interno, con el de Alemania de la primera posguerra, concluía que el de México resultaba más costoso, es
Gráfico t

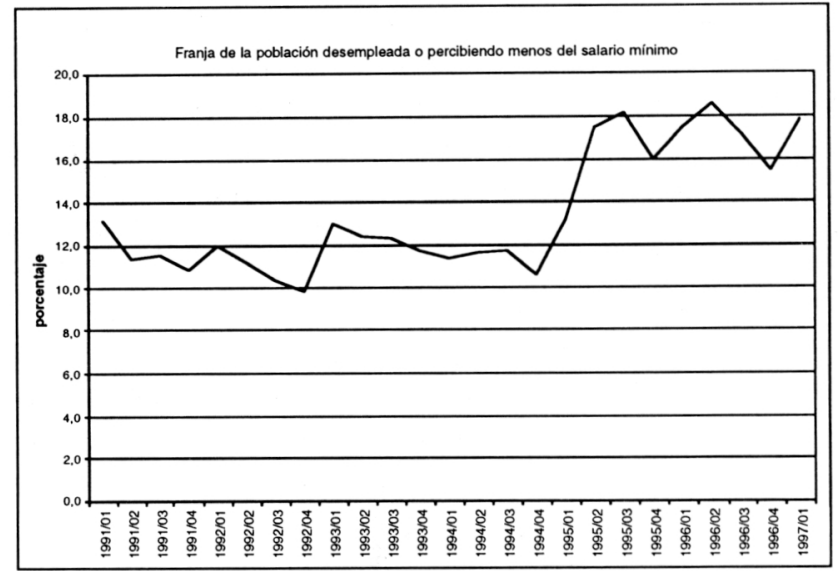

necesario ver que a doce años de ese diagnóstico el PIB es inferior al de inicio de los ochenta ${ }^{17}$. Al final de la crisis, si así se le llaman a los días que corren, la reconcentración del ingreso alcanza niveles sin parangón en la historia moderna.

\section{A MANERA DE CONCLUSIÓN}

La economía mexicana encara problemas exacerbados por la combinación de expectativas desmedidas hacia las virtudes de la liberalización económica, con la ausencia de medidas orientadas a la consolidación del aparato productivo interno, pues sin mercado interno creciente no hay economía exitosa ${ }^{18}$.

La experiencia de México demuestra que no fue suficiente con la reducción de obstáculos a la eficiencia y que, por lo tanto, hay lugar para la discusión y la puesta en práctica de políticas de fomento. Es decir, pareciera preciso abordar explícitamente temas como el empleo o el papel que habrá de desempeñar el sistema fiscal, no sólo como recaudador sino como promotor de la actividad económica al dotarse de una orientación que consolidase los instrumentos y mecanismos para financiar el desarrollo ${ }^{19}$.

El TLC, a lo largo de sus años de vigencia, ha beneficiado a la actividad exportadora y, en esa medida, al avance en la eficiencia de ciertas actividades manufactureras. Es eso, y no mucho más, lo que debió esperarse del acuerdo y lo que hoy debe ser reconocido sin esperar que genere, por sí mismo, círculos virtuosos que, sin la conjunción con otras políticas, seguirán estando sólo en el imaginario.

Con la reflexión anterior están ligados los elementos referidos al mercado de trabajo, que se han incluido en el presente texto, los mismos que permiten asegurar que la

15. Tello, Carlos, "La economía mexicana: hacia el tercer milenio", Nexos, núm. 232, mayo de 1997.

16. Valle, Alejandro, "Diferencias de salarios medios entre países: Canadá, Estados Unidos y México”, en Martín Pablo y Salas, Carlos, Cuestiones de integración económica, UNAM-UAM, Madrid, 1996.

17. Cordera, Rolando, "Después del vuelco", en Situación Latinoamericana, núm. 33, CEDEAL, Madrid, 1997.

18. Krugman, Paul, El internacionalismo moderno, Crítica, Barcelona, 1997.

19. González Tiburcio, Enrique, y Zepeda, Pedro José, "La política económica postelectoral”, en Etcétera, núm. 234, México, agosto de 1997. 
puesta en operación del TLC ha significado pocos cambios sobre el empleo y la remuneración al trabajo en México. Asimismo, que las tendencias ahí reflejadas responden más al cambio de modelo de desarrollo verificado desde mediados de los años ochenta que a la firma del acuerdo. En el tránsito hacia un nuevo modelo, o hacia una nueva mezcla de políticas económicas en torno a ciertas reglas maestras, lo que se ha hecho evidente es la incapacidad de creación de empleo asalariado, así como una mayor seg. mentación, tanto en términos de ocupación como de ingresos, de los mercados de trabajo en México.

La poca incidencia del TLC en el mapa del empleo en México puede, sin embargo, tener matices en lo que a la distribución espacial se refiere. Es decir, sería preciso un estudio desagregado por regiones para ver si la concentración de las actividades maquiladoras que se verificó desde los años ochenta se ha incrementado a partir de la puesta en funcionamiento del Tratado.

Por otro lado, la ausencia de políticas para elevar las tasas de ahorro e inversión, de capital físico y humano que hagan posible la absorción tecnológica, así como aquellas orientadas al crecimiento de exportaciones netas (de importaciones netas), resulta ya insostenible.

En suma, atendiendo a la necesidad de superar los vacíos de la política económica argumentados en líneas anteriores, es que podría resultar plausible revertir una situación de contracción del empleo y los salarios. Y en el mismo sentido, es posible que el mayor obstáculo para ir en la senda que perfilan esas medidas, que sin duda trascienden al TLC, pueda encontrarse más en las restricciones institucionales internas, que impiden actuar efectivamente al Estado mexicano como coordinador del proceso de desarrollo, que en los límites externos.

\section{BIBLIOGRAFÍA}

CoRdera CAmpos, Rolando, 1995: la economía mexicana en peligro, México, Cal y Arena, 1997.
Cordera, Rolando, “Después del vuelco", en Situación Latinoamericana, núm. 33, CEDEAL, Madrid, 1997.

González Tiburcio, Enrique, y ZepedA, Pedro José, "La política económica postelectoral", en Etcétera, núm. 234, México, agosto de 1997.

IBARRA, DAVID, "La economía mexicana: ¿en dónde estamos?”, en Nexos, núm. 235, julio de 1997.

InstituTO NACIONAL DE EsTAdísticA, GEOGRAFÍA E INFORMÁTICA, Encuesta Nacional de Empleo Urbano 1995, México, 1996.

Krugman, Paul, "El internacionalismo moderno”, Crítica, Barcelona, 1997.

López, Julio, "La industria mexicana ante la crisis" UACPyP-UNAM, México, (mimeo) 1996.

LORIA, EDUARDO, "Los efectos de la apertura comercial sobre el empleo y la balanza comercial del sector manufacturero mexicano, 1986-1996" en Ruesga, Santos (comp.), Integración Económica Regional, (en prensa) Madrid, 1997

NACIONAL FINANCIERA, La economía mexicana en cifras 1996, México, 1997.

ROS, JAIME, "La crisis mexicana y la reforma de la política macroeconómica", en Pensamiento Iberoamericano, núm. 27, CEDEAL, enero-junio de 1995.

Rendón, T. y SALAS, C. "La evolución del empleo en México: 1895-1980"; Estudios Demográficos y Urbanos, Vol II, núm. 2, El Colegio de México, 1987.

Rendón, Teresa y Salas, Carlos, "El impacto probable del TLC sobre el empleo no agrícola en México", en Martín, Pablo y Salas, Carlos (comps.), Cuestiones de integración y desarrollo, UNAM-UAM, Madrid, 1996.

Ros, JAIME, "La enfermedad mexicana", en Nexos, núm. 235, México, julio de 1997.

Tello, Carlos, "La economía mexicana: hacia el tercer milenio", Nexos, núm. 232, mayo de 1997.

Valle, Alejandro, "Diferencias de salarios medios entre países: Canadá, Estados Unidos y México”, en Martín Pablo y Salas, Carlos, Cuestiones de integración económica, UNAM-UAM, Madrid, 1996.

\section{RESUMEN}

Este artículo presenta la evolución reciente de la economía mexicana en el marco del proceso de integración en que está inserta. Especialmente analiza las consecuencias de la crisis de 1995 para las relaciones externas de México y para la evolución del Trabajo de Libre Comercio que lo vincula con Canadá y Estados Unidos. Finalmente se refiere a las repercusiones de este proceso en el empleo.

Palabras clave: México, integración económica, comercio, Tratado de Libre Comercio, empleo.

\section{ABSTRACT}

This article presents recent evolution of Mexican economy on the frame of its integration process. I focuses on consequences of 1995 crisis for Mexican international relations and for evolution of the TLC. Finally, it refers to its echoes on the employment.

Key words: Mexico, economical integration, commerce, TLC, employment. 